\title{
Chemical Speciation: A Strategic Pathway for Insightful Risk Assessment and Decision Making for Remediation of Toxic Metal Contamination
}

\author{
Haruna Adamu ${ }^{1,3}$, Leke Luter ${ }^{1,4}$, Mohammed Musa Lawan ${ }^{1,5} \&$ Bappah Adamu Umar ${ }^{2,6}$ \\ ${ }^{1}$ Department of Chemistry, University of Aberdeen, UK \\ ${ }^{2}$ Department of Geology and Petroleum Geology, University of Aberdeen, UK \\ ${ }^{3}$ Department of Environmental Management Technology, Abubakar Tafawa Balewa University, Nigeria \\ ${ }^{4}$ Department of Chemistry, Benue State University, Nigeria \\ ${ }^{5}$ Department of Chemistry, Yobe State University, Damaturu, Nigeria \\ ${ }^{6}$ National Centre for Petroleum Research and Development, Energy Commission of Nigeria, Abubakar Tafawa \\ Balewa University Research Centre, Nigeria \\ Correspondence: Haruna Adamu, Department of Chemistry, University of Aberdeen, Scotland, UK; Department \\ of Environmental Management Technology, Abubakar Tafawa Balewa University, Bauchi State, Nigeria. Tel: \\ 44-776-717-3610. E-mail: aisonhardo2003@yahoo.com
}

Received: April 16,2013 Accepted: May 20,2013 Online Published: June 25, 2013
doi:10.5539/ep.v2n3p92
URL: http://dx.doi.org/10.5539/ep.v2n3p92

\begin{abstract}
Industrial and anthropogenic activities have resulted in high levels of metallic contaminants in the environment, thus creating imbalance in the biotic and abiotic regimes of the ecosystem. This has remained as a stabbing problem in the mind of environmental and agricultural scientists, since metallic contaminants unlike biodegradable contaminants are persistent in affecting the biophysical population of our environment. This problem requires an insightful assessment before the best remediation option can be selected appropriately. In this paper, we present an overview of chemical speciation and its adaptations in environmental cleanup for achieving result oriented remediation technique.
\end{abstract}

Keywords: metallic contaminants, speciation, remediation

\section{Introduction}

Contamination of the surface of the earth by metallic contaminants from human activities has been significant (Markham, 1994) and thus, regimes of ecosystem of the aquatic and terrestrial environment of the earth's surface are burdened with a range of metallic pollutants/contaminants. For example, many materials were processed in significant quantities to support the developing technologies underpinning the growth of the developed countries (Markham, 1994; Macklin, 1992). The extraction and utilization of metals as major components of infrastructure and in high value goods became the cornerstone of the development of human civilization (Wedepol, 1991).

With the advent of the industrial revolution in Western Europe, e.g. the availability of steam powered devices, the utilization of fossil fuels increased the capacity of society to manipulate the Earth's resources and process materials (Wedepol, 1991). The net impact was to advance civilization and enhance socio-economic well-being of society and as a direct result of the incomplete efficiency of these processes, release of residual materials to the atmosphere, aquatic and terrestrial environment occurred (Macklin, 1992).

Through human activities, contamination of the Earth's surface by metallic contaminants developed from localized problems associated with mining and initial ore processing, e.g. like the Zamfara $\mathrm{Pb}$ poisoning in northern Nigeria (WHO Lead NGR, 2010), through to large scale manipulation and refining, construction, manufacture and finally to waste disposal. This, coupled with the focusing of population center into industrialized cities, resulted in an increased burden on the environment (Lowe \& Bowlby, 1992). The consequence of this has increased awareness of human and industrial impacts on environmental systems at the local and global scale. This has resulted in efforts to manage and improve the degraded quality of aquatic and 
terrestrial systems (Ozdes et al., 2011; Thornton, 1996; Cairney, 1995; Bora, 1998).

The increase in human stress on sensitive surface environments requires the development of reliable management options for soil and water systems, which are often contaminated with a mix group of physical and chemical components. Contamination from processing residues, direct deposition and accidental releases of organic and metallic species create a wide spectrum of environmental hazards (Hagelstein, 2009; Cairney, 1995; Ferguson et al., 1998). An in-depth understanding and appropriate remediation of these situations would rely on an intimate mix of science, technology and socio-economic factors.

It is within this content that the speciation of metallic contaminants provides both the potential hazard (mobility, reactivity, toxicity) (Centeno, 2003) and thus, the pathway to a technological acceptable solution (remediation option). The factors influencing the speciation and changes with both time and environmental conditions provide the greatest challenges and opportunity for environmental science and technology. While the contamination of the surface of the earth by human intervention is a relatively old phenomenon, the evaluation, assessment and remediation of negative impact are relatively recent (Morgan, 2008; Khan et al., 2004; Cairney, 1995; Johnson, 1993; Bernhard et al., 1996). As such, this paper provides an overview of the content associated with metallic contamination and highlights the significant role of metal speciation in risk insight of contamination scenario and achieving result-oriented remediation (if contamination necessitates).

\section{Definition of Chemical Speciation}

The determination of distinct chemical species often referred to as speciation analysis is now widely acknowledged to be of vital importance in environmental chemistry (Hill, 1997). The term chemical speciation may encompass both functionally defined speciation, i.e. the determination of species that are, for example, available to plants or present as exchangeable forms and operationally defined speciation which refers to the determination of extractable forms of an element (Hill, 1997). While it is often possible to define a particular compound or oxidation state when dealing with solutions, for example, natural waters, it is far more difficult to characterize the actual chemical form of an element in solids such as soils and sediments (Hill, 1997). Thus, speciation tends to be defined somewhat differently by research workers to reflect their field of study. However, one of the most comprehensive formal definitions of speciation is the one recommended by the International Union of Pure and Applied Chemistry (IUPAC), which states that speciation is the process yielding evidence of atomic or molecular form of an analyte (Lobinski \& Szpunar, 1999). As such, this definition was subsequently elaborated conspicuously as the specific form of an element defined as to electronic or oxidation state, complex or molecular structure and isotopic composition (Templeton et al., 2000). In addition, International Union of Pure and Applied Chemistry (IUPAC) has recently evaluated and provided a definition of speciation as an analytical activity of identifying and/or measuring the quantities of one or more individual chemical species in a sample; the chemical species are specific forms of an element defined as to isotopic composition, electronic or oxidation state, and/or complex or molecular structure; the speciation of an element is the distribution of an element amongst defined chemical species in a system (Clough et al., 2012). With this elaboration, chemical speciation has now clearly demarcated itself from chemical fractionations, which were previously interchangeable and confusing.

The determination of such specific chemical entities is of course not new to analytical chemists. For example, the determination of $\mathrm{NO}_{3}{ }^{-}, \mathrm{NO}_{2}{ }^{-}, \mathrm{NH}_{4}{ }^{+}$, and $\mathrm{NH}_{3}$ where the nitrogen is characterized into its most environmentally important forms is long established (Hill, 1997). However, the characterization of metallic contaminants does not have the same history, although with the increased awareness of the importance of chemical speciation in terms of toxicity, mobility, bioavailability, reactivity and persistence in the environment, a range of sensitive yet specific analytical techniques have now been developed to address a wide range of environmental complex problems.

\section{Analytical Approaches to Speciation Studies}

Many analytical techniques have been developed for chemical speciation of elements in the environmental samples: typically, sequential leaching methods (Koschinky \& Hein, 2003), hyphenated techniques such as GC-ICP-MS (analysis of organometallic elements) (Hirata et al., 2006), X-ray spectroscopic techniques (Ohnuki et al., 2005). These methods of analysis provide significant information on the chemical forms of elements in the environment (Hirose, 2006). In terms of analysis, it is possible to identify and quantify species in environmental samples. Speciation studies on environmental samples were initially focused mainly on separation of specific elemental species is groups of species (Ebdon et al., 1987; Harrison \& Rapsomaniskis, 1989). Species separation is achieved mainly by one of the following well known techniques: liquid chromatography (LC), gas chromatography (GC), capillary electrophoresis (CE), and gel electrophoresis (GE) (Hill, 1997). The choice is 
determined by the chemical properties of the species, the available skills and infrastructure in the laboratory, and last but not the least, the available resources.

However, during the last two decades substantial progress was made in incorporating separation methods with powerful detection methods for reliable quantitative measurements. Majority of work performed coupling GC with atomic spectrometry has so far been achieved using flame spectrometry as a detector (Webster \& Karmahan, 1992). This approach has been used most commonly for analytes that are present in relatively high concentration e.g. determining Organo-Lead species in fuel or roadside dust (Hill, 1997). A potential limitation of using GC is that often the sample must be derivatised to make it volatile enough for analysis. This can greatly increase sample preparation time, which may cause loss of analyte and uncertainty about the identity of the original species in the sample. To deal with such problems, high performance chromatography (HPLC) is one of the most common methods used for separation of non-volatile analytes and has been extensively coupled to atomic spectroscopy for quantification. There are a large number of resin supports that are being in use as the stationary phase with anion exchange, cation exchange, size exclusion, chelating and reversed phase, e.g. octadecylsilane which is often used in conjunction with an ion pairing reagent such as tetrabutylammonium phosphate, diethyl dithiocarbamate or 8-hydroxyquinoline to enhance separation of analytes. In this way, analytes with different oxidation states e.g. $\mathrm{Cr}^{3+}$ and $\mathrm{Cr}^{6+}$ are separated and quantified (Peter, 2001). In the same vein, arsenic has been speciated into $\mathrm{As}^{3+}, \mathrm{As}^{5+}$, monomethyl arsonic acid, dimethyl arsinic acid and arsenobetaine using an anion exchange resin with an ammoniacal potassium sulphate mobile phase (Hill, 1997; Ebdon et al., 1987). In addition, the HPLC separation of arsenic species has been coupled with online microwave digestion and hydride generation to facilitate the direct determination of reducible and non-reducible forms of arsenic (Ure \& Davidson, 1995). The other convenient method for on-line coupling are inductively coupled plasma atomic emission spectrometry (ICP-AES), which sometimes referred to as ICP-optical emission spectrometry (ICP-OES) and inductively coupled plasma mass spectrometry (ICP-MS). ICP-MS has enabled multi-elemental detection, isotopic discrimination with extremely high sensitivity. Moreover, HPLC and GC were successfully coupled to ICP-MS and now referred to as hyphenated technique for speciation analysis. This technique is now the most frequent used analytical technique for speciation purposes. For instance, Fan et al. (2012) determined the concentration of $\mathrm{Cu}$ and its chemical forms in soil extracts using inductively coupled plasma optical emission spectrometry (ICP-OES).

Similarly, eletroanalytical method, for example, anodic stripping voltammetry (ASV) and other electronalyical techniques such as amperometry potentiometry have also been applied for quantification of the various oxidation states of an element. $\left(\mathrm{Fe}^{2+} / \mathrm{Fe}^{3+}, \mathrm{Cr}^{6+} / \mathrm{Cr}^{3+}, \mathrm{Tl}^{3+} / \mathrm{Tl}^{+}, \mathrm{Sn}^{4+} / \mathrm{Sn}^{2+}, \mathrm{Mn}^{4+} \mathrm{Mn}^{2+}, \mathrm{Sb}^{5+} / \mathrm{Sb}^{3+}, \mathrm{As}^{5+} / \mathrm{As}^{3+}\right.$, and $\left.\mathrm{Se}^{6+} / \mathrm{Se}^{4+}\right)$ its organometallic species, or metal complexes (Harrison \& Rapsomaniskis, 1989; Caroli, 1996; Quevanviller \& Maier, 1994).

Of recent, various mathematical modeling and computer aided programs have been developed for speciation analysis. For example, in many studies in which metal speciation in soil solution is connected to metal uptake by target organism, the Free Ionic Activity Model (FIAM) was used (Campbell, 1995). This model was later extended into the Biotic Ligand Model (BLM) in order to include the influence of competing cations like $\mathrm{Ca}^{2+}$ and $\mathrm{H}^{+}$(Di-Toro et al., 2001). With more advances in this aspect, Donnan Membrane Technique (DMT) Diffusive Gradient in Thin films (DGTs) have been developed and successfully applied in speciation analysis. Similarly, Windermere Humic Aqueous Model (WHAM VII) is the latest version of the mathematical model and computer aided program, which is developed and thus world widely embraced (Tipping, 1998). The WHAM VII model contains database for cation binding to humic and fulvic acids, including all rare earth elements and silver. It simulates the precipitation of iron (III) and aluminium hydroxides, and binding of ions to precipitate. The binding activity of dissolved organic matter is used to generate distributions of predicted free ions concentrations (Lofts \& Tipping, 2011).

\section{Role of Metal Speciation in Risk Insight and Remediation}

The identification and quantification of specific metal species in environmental samples is no longer an academic curiosity but also a substantial deal of particular interest to researchers in industries, as well as government agencies and legislative bodies for environmental pollution/contamination monitoring and management. However, the capacity and importance of metal speciation have not yet considered and incorporated in risk insight and remediation strategies, because it has not been appraised to be amongst the prerequisite approaches to determining the most technically and cost effective method for remediating a particular contaminated site(s) (if need there be). Although, remediation procedures and techniques are becoming increasingly more costly, however, many of today's remediation costs can be minimized without jeopardizing effectiveness by first gaining a better understanding of contamination scenario by metal speciation. This in turn, 
will allow remediation experts to put in appropriate remediation option to certain contaminants, which will undoubtedly respond efficiently and effectively upon the metallic contaminants. More explicitly, metal speciation research is needed to improve the ability of decision makers of environmental pollution/contamination to evaluate the risks of metallic contamination and develop effect and economic remediation strategies. The speciation or chemical form of metals governs its fate, toxicity, mobility and bioavailability in contaminated soils and water. To assess these chemical properties and to accurately gauge their impact on human health and the environment, metallic contaminants need to be characterized into different species. The importance of metal speciation research to the development of pollution law and control technologies (remediation options) is increasingly evident (USEPA, 2008a). Research on the chemical, biological, toxicological, and ecological effects of chemical species in the environment and methodology for the determination of chemical species and their bioavailability are providing new insight on previously hard to understand problems. For instance, studies conducted by the Land Research Program in the United State of America (USA) have enabled EPA to better predict the mobility, bioavailability and fate of metallic contaminant in environmental systems and developed cost-effective remediation strategies in response (USEPA, 2008b).

However, before remediation exercise to be undertaken or not, a reliable and proper analysis and identification of the contamination problem must be carried out, both its exact nature and extent. The more thorough the analysis the less likely the cost surplus will surface at a later stage. This involves site investigation by chemical speciation (Van Loon, 1975) and therefore, metal speciation is at best a difficult task but worth doing for appropriate remedy option selection and risk insights assessment.

Remediation of sites contaminated with metallic contaminants is a complex problem as the metallic contaminants exist in different oxidation states, inorganic and organic complexes and the degree of toxicity depends on which of those chemical species or forms of the contaminants (Hill, 1997). In turn, therefore, the metallic contaminants should be characterized first into their different chemical species if a reliable management option is to be best selected for achieving a result-oriented remediation technique. It is within this context that the chemical speciation of metallic components provides both the potential hazard (mobility and toxicity) and the pathway to a technological acceptable solution to the contamination scenario (Todd \& Raina, 2003). Thus, involvement of chemical speciation in the remediation of contaminated site(s) is of great importance since effectiveness and efficiency of any remediation technique rely on reaction specificity. Because, this is found and applied in medical sciences for the treatment/medication of a particular illness/disease by medical doctors, where a patient must first be diagnosed, after which prescribed medicine(s) or drug(s) would specifically act upon the diagnosed illness/disease and systematically remove the illness/disease shortly afterwards. With this analogy, generation of data from chemical speciation will definitely provide important supporting information for treatment proposal (remediation) and risk assessments.

Remediation of metallic contaminants can only be brought about by their removal from the site or by establishing conditions which favor their retention in the solid phase. This can be achieved by ensuring that the described conditions for the initial removal or immobilization process are met and maintained over a suitable period of time (Morgan, 2008; Pratt, 1993). In the contest of soil and water contamination and remediation, we need to consider all aspect of transfer of metallic contaminants between phases (absorption, solubility, coagulation, coprecipitation, volatilization), transformation of species by electron transfer, ligand exchange availability and bioaccumulation and physical transport processes affecting a particular component of the metal species or group of interest (Tangahu et al., 2011; Morgan \& Stumm, 1991; Sparks, 1995; Hering, 1995). This will impact on the influence of the contaminant status, reaction within the deposited environment, suitability and effectiveness of remediation process and long-term behavior of remediation results essentially a true four dimensional context. To adequately address this, data are required from chemical speciation which will allow appropriate assessment to be made (Tangahu et al., 2011; Mach et al., 1996). Therefore, when chemical speciation is applied in an appropriate manner, information is always gained and its role in subsequent interpretation should be the driving force for considering any remediation technique. For example, chromium exists as hexa and trivalent oxidation state which are the key features of its beneficial and detrimental contribution, and also its geochemical behavior in surface environment. Simply, toxic chromium (VI) is generally found as a mobile component in surface environments, while chromium (III) is an essential nutrient and relatively immobile in these systems (Miller, 1991). With this information from chemical speciation of chromium, the most common approach to treat $\mathrm{Cr}(\mathrm{VI})$ contamination is to reduce $\mathrm{Cr}(\mathrm{VI})$ to $\mathrm{Cr}(\mathrm{III})$ following by precipitation of $\mathrm{Cr}(\mathrm{III})$ (Ozer et al., 1997).

Furthermore, characterization of metallic contaminants through chemical speciation research into free ions of different oxidation states, inorganic and organic complexes will enable remediation experts to better predict the 
mobility, bioavailability and fate of metallic contaminants in surface environmental systems and developed effective and economic remediation strategies in response like the earlier one presented in the case of chromium (VI) contamination. It is generally accepted that the bioavailability of metallic contaminants and their physiological and toxicological effect depend on the actual species present and not on the total concentration (Brummer et al., 1986; Hendershot et al., 2000). More precisely, for example, Mn(III) species are more toxic than $+2,+4,+6$ and +7 oxidation states. Organometallic of $\mathrm{Hg}, \mathrm{Pb}$ and $\mathrm{Sn}$ are more toxic than inorganic forms. In contrast, inorganic species of $\mathrm{Cu}$, As and $\mathrm{Al}$ are more toxic than organic ones (Chutia et al., 2009; Tangahu et al., 2011; Hill, 1997). In addition, distribution of a metallic contaminant amongst different species profoundly affects its transport by determining such properties as-oxidation state (gauge for toxicity, solubility) and diffusion coefficient (organic complexes, key determinant for macro-molecular size) (Sager, 1992). In addition, as well as in the practical term, the elevated levels of $\mathrm{Pb}$ found in the water quality test during the investigation of the environmental impact of Rhandirmwyn Mine in South Wales, UK suggests that anglesite (one of the chemical forms of $\mathrm{Pb}$ ) which was the most common occurring form observed during the SEM analysis and found to be more soluble than all the forms observed, may be responsible for the elevated concentration of $\mathrm{Pb}$ in the water of the major river and the major source of water for public utilization in the area. Therefore, the situation at which $\mathrm{Pb}$ becomes most toxic ecotoxicologically depends on its chemical form which exists in the environment, which is the centripetal force that was used to direct decision towards arriving at an appropriate conclusion that the river water and the Rhandirmwyn Mine sites require remediation treatments (Umar, 2010). Upon all these information, it is quite clear that chemical speciation drastically models contaminants behavior and thus, the approach can be used in decision making in choosing and developing reliable remediation option.

Much more, without a full understanding of the local interaction of the contaminants and potential ecological impacts the derivation of total concentration levels for contaminants is meaningless (Wuana \& Okieimen, 2011; Martins \& Bardos, 1995; Peter \& Shem, 1995). In recognition of this issue, regulatory regimes worldwide are now moving towards advocating a risk-based assessment process for contaminated sites (Lai et al., 2010; Fergusen et al., 1998). This is a crucial point for the speciation community as it will derive the development of appropriate testing systems, and stimulate the collection of data linking speciation to environmental impact assessment of metallic contaminants. By applying these criteria to the investigation process and incorporating them in the evaluation of remediation targets, the risk-based approach will allow a more effective remediation strategy to be defined and within the context of limitation of the site investigation (sampling intensity versus cost), will provide a more realistic evaluation of the volumes of material/site required to be remediated.

The identification of contamination problem is only a small part of the contamination scenario. The decision to remediate must come from the information gained on the chemical speciation research of metallic contaminants, as it provides predictive insights on toxicity, mobility, bioavailability and fate of metallic contaminants. Besides, the influence of speciation on the behavior of metal species in contaminated soils/water is fundamental to the response of contaminants to remediation technique(s) (Wuana \& Okieimen, 2011; Newson, 1992).

\section{Conclusion}

With the good understanding of the capacity of chemical speciation of environmental pollutants/contaminants, from the laboratory to field scale evaluation of contaminants behavior and the approach to be taken to assess and recommend the reliability of remediation option will no longer be a hard to understand problem, since chemical (oxidation/valence state) forms determine toxicity; chemical forms determine the mobility of an element in the environment; speciation of metals can affect the bioavailability of metals and therefore their associated risks. By implication this indicates that total concentrations of toxic metals in the environment should not be generalized as threshold for remedial action, but rather the chemical forms of the toxic metals. Hence, the speciation community has a sustained contribution to the management of metal contamination of the natural environment. In a nutshell, chemical speciation has a pivoted role to play in hazard and risk assessment, remediation strategies and in the long term management of remediated sites.

\section{References}

Bernhard, M., Brinckman, F. E., \& Sadler, P. J. (1996). The importance of speciation in environmental processes. Berlin: Springer-Verlag.

Bora, A. (1998). Green to contaminated and derelict land (pp. 10-18). London: Thomas Telford.

Brummer, G. W. (1986). In M. Bernhard, F. E. Brickman, \& P. J. Sadler (Eds), The importance of chemical speciation in the environmental process (p. 170). Berlin, Heidel berg, New York: Springer.

Cairney, T. (1995). There use of contaminated land. Chichester: John Wiley. 
Campbell, P. G. C. (1995). Interactions between trace metals and aquatic organisms: a critique of the free ion activity model. In A. Tessier, \& D. R. Turner (Eds.), Metal speciation and bioavailability in aquatic systems, 3, 45-102.

Caroli, S. (1996). Element speciation in bioinorganic chemistry. Wiley.

Centeno, J. A. (2003). Speciation of trace elements and toxic metal ions species. Retrieved from www.cprm.gov.br/publique/media/jose-speciation_lecture.pdf

Chutia, P., Kato, S., Kojima, T., \& Satokawa, S. (2009). Arsenic adsorption from aqueous solution on synthetic zeolite. J. Hazard. Mat., 162(1), 440-447. http://dx.doi.org/10.1016/j.jhazmat.2008.05.061

Clough, R., Lindsay, R., Drennar, H., Harrington, C. F., Hill, S. J., \& Tyson, J. F. (2012). Atomic spectrometry Update: Elemental speciation. J. Anal. Atomic Spectr., 27, 1185-1224. http://dx.doi.org/10.1039/c2ja90037h

Di-Toro, D. M., Allen, H. E., Bergman, H. L., Meyer, J. S., Paqiun, P. R., \& Santore, R. C. (2001). Biotic Ligand model of the acute toxicity of metal. 1. Technical basis. Environ Toxicol Chem., 20, 2383-2396. http://dx.doi.org/10.1002/etc.5620201034

Ebdon, L., Hill, S. J., \& Ward, R. (1987). Chemical speciation of metal species in surface environment. Analyst, 112, 1. http://dx.doi.org/10.1039/an9871200001

Fan, J., He, Z., Ma, L. Q., Nogueira, T. A. R., Wang, Y., Liang, Z., \& Stoffela, P. J. (2012). Calcium water treatment residue reduces copper phytotoxicity in contaminated sandy soils. J. Hazard. Mat., 199-200, 375-382. http://dx.doi.org/10.1016/j.jhazmat.2011.11.030

Feng, D. X., Dang, Z., Hung, W. L., \& Yang, C. (2009). Chemical speciation of fine particle bound trace metals. Int. J. Environ. Sci. Technol., 6(3), 337-346.

Ferguson, C., Dermendraid, K., Freier, K., Jensen, B. K., Jensen, J., Kasamas, H. ... Vegter, J. (1998). The risk assessment for contaminated sites in Europe, Volume1, scientific basic. Nottingham: LQM Press.

Hagelstein, K. (2009). Globally sustainable manganese metal production and use. J. Environ. Manag., 90(12), 3736-3740. http://dx.doi.org/10.1016/j.jenvman.2008.05.025

Harrison, R. M., \& Rapsomaniskis, S. (1989). Environmental analysis using chromatography interfaced with atomic spectroscopy. Ellis Harwood.

Hendershot, W. H., Murray, P., \& Ge, Y. (2000). Trace metal speciation and bioavailability in urban soils. Environ. Pollut., 107,137-144. http://dx.doi.org/10.1016/S0269-7491(99)00119-0

Hering, J. G. (1995). In H. E. Allen, C. P. Huang, G. W. Bailey, \& A. R. Bower (Eds.), Metal speciation and contaminated soil (pp. 59 -86). Boca Raton, FL: CRC Press.

Hill, S. J. (1997). Speciation of trace metals in the environment. Chemical Society Review, 26, 291-298. http://dx.doi.org/10.1039/cs9972600291

Hirata, S., Toshimitsu, H., \& Aihara, M. (2006). Determination of arsenic species in marine samples by HPLC-ICP-MS. Anal. Sci., 22, 39-43. http://dx.doi.org/10.2116/analsci.22.39

Hirose, K. (2006). Chemical speciation of trace metals in seawater: A review. Anal. Sci., 22, 1055-1062. http://dx.doi.org/10.2116/analsci.22.1055

Johnson, S. (1993). Remedial processes for contaminated land (pp.1-17). Institute of chemical engineers, Rugby, Warwickshire.

Khan, F. I., Husain, T., \& Hejazi, R. (2004). An overview and analysis of site remediation technologies. $J$. Environ. Manag., 71, 95-122. http://dx.doi.org/10.1016/j.jenvman.2004.02.003

Koschinsky, A., \& Hein, J. R. (2003). Uptake of elements from seawater by ferromanganese crusts: Solid phase association and seawater speciation. Mar. Geol., 198, 331-351. http://dx.doi.org/10.1016/S0025-3227(03)00122-1

Lai, H-Y., Hseu, Z-Y., Chen, T-C., Chen, B-C., Guo, H-Y., \& Chen, Z-S. (2010). Health risk-based assessment and management of heavy metals-contaminated soil sites in Taiwan. Int. J. Environ. Res. Pub. Heal., 7(10), 3595-3614. http://dx.doi.org/10.3390/ijerph7103596

Lobinski, R., \& Szpunar, J. (1999). Biochemical speciation analysis by hyphenated techniques. Anal. Chim. Acta., 400, 321-332. http://dx.doi.org/10.1016/S0003-2670(99)00628-5 
Lofts, S., \& Tipping, E. (2011). Assessing WHAM/Model VII against field measurement of free metal ion concentrations: Model performance and the role of uncertainty in parameters and inputs. Environ. Chem., 8(5), 501-516. http://dx.doi.org/10.1071/EN11049

Lowe, M. S., \& Bowlby, S. R. (1992). Environmental issues in the 1990s (pp. 117-130). Chichester: John Wiley.

Mach, M. H., Nott, B., Scott, J. W., Maddalone, R. F., \& Widdon, M. (1996). Metal speciation and contaminated soils. Amended with sewage sludge. Water, Air, Soil pollution, 90, 269. http://dx.doi.org/10.1007/BF00619287

Macklin, M. (1992). Managing the human impact on the natural environment: Pattern and processes. London: Belhaven press.

Markham, A. (1994). A brief history of pollution. London: Earths scan publications.

Martins, I., \& Bardos, P. (1995). A review of full scale treatment technologies for the remediation of contaminated soil. EPP publications, Richmond surrey.

Miller, B. S. (1991). Heavy metals in the environment (pp. 199-203). Edinburg: CEP Consultants..

Morgan, J. J., \& Stumm, W. (1991). Metals and their compounds in the environment (pp. 67-103). Weinhein: $\mathrm{VCH}$.

Morgan, P. (2008). Contaminated land remediation technology. Land remediation yearbook (pp.39-42). Retrieved from www. eic-yearbook.co.uk

Newson, M. (1992). Managing the human impact on the natural environment: Pattern and processes (pp. 14-36). London: Belhaven press.

Ohnuki, T., Yoshida, T., Nankawa, T., Ozaki, T., Kozai, N., Sakamono, F., ... Francis, A. J. (2005). A continuous flow system for in-situ XANES measurements of change in oxidation state of $\mathrm{Ce}$ (III) to $\mathrm{Ce}$ (IV). J. Nucl. Radiochem. Sci., 6, 65-67.

Ozdes, D., Diran, C., \& Senturk, B. H. (2011). Adsorptive removal of Cd (II) and Pb (II) ions from aqueous solutions by using Turkish illitic clay. J. Environ. Manag., 92(12), 3082-3090. http://dx.doi.org/10.1016/j.jenvman.2011.07.022

Ozer, A., Altundogan, H. S.,Erdem, M., \& Tumen, F. (1997). Chemical speciation and remediation of metallic contaminants. Environ. pollut., 97,107

Peter R.W., \& Shem, L. (1995). In H. E. Allen, C. P. Huang, G. W. Bailey, \& A. R. Bowers (Eds), Metal speciation and contamination of soil (pp. 255-274). Boca Raton, FL: CRC press.

Peter, V. D. (2001). Trace element speciation for environment, food and health (pp. 233-235). Thomas Graham house, Cambridge, UK: Royal society of chemistry.

Pratt, M. (1993). Remedial process for contaminated soils (p. 14). Rugby Warwickshire.

Quevanviller, P., \& Maier, E. A. (1994). Research trends in the field of environmental analysis. European commission, Brussels.

Reeder, R. J., \& Schoonan, M. A. A. (2006). Metal speciation and its role in bioaccessibility and bioavailability. Reviews in Mineralogy and Geochem., 64, 312-319. http://dx.doi.org/10.2138/rmg.2006.64.3

Sager, M. (1992). Hazardous metals in the environment: Techniques and instruments in analytical chemistry (pp. 133-175). Amsterdam: Elsevier. http://dx.doi.org/10.1016/S0167-9244(08)70106-9

Sparks, D. L. (1995). In H. E. Allen, C. P. Huang, G. W. Bailey, \& A. R. Bower (Eds.), Metal speciation and contaminated soil (pp. 35-58). Boca Raton, FL: CRC Press.

Tangahu, B. V., Abdullah, S. R. S., Basri, H., Idris, M., Anuar, N., \& Mukhlisin, M. (2011). A review on heavy metals $(\mathrm{As}, \mathrm{Pb}$ and $\mathrm{Hg}$ ) uptake by plants through phytoremediation. Int. J. Chem. Eng., 2011, 1-31. http://dx.doi.org/10.1155/2011/939161

Templeton, D. M., Ariese, F., Cornelis, R., Danielson, L. G., Muntan, H., Van Leuwen, H. P., \& Labinski, R. (2000). Chemical speciation and Fractionation. Pure Appl. Chem., 72, 1453-1470. http://dx.doi.org/10.1351/pac200072081453

Thornton, I. (1996). Remediation of metallic contaminants in natural environment. Appl. Geochem, 11, s335.

Tipping, E. (1998). Humic ion-bioding model VI: An improved description of the interaction of proton and metal ions with humic substances. Aquat Geochem., 4, 3-48. http://dx.doi.org/10.1023/A:1009627214459 
Todd, R. S., \& Raina, M. M. (2003). Impact of metals on the biodegradation of organic pollutants. Environ. Health Perspectives, 111(8), 1093-1101. http://dx.doi.org/10.1289/ehp.5840s

Umar, B. A. (2010). Environmental Impact and Regeneration of Rhandirmwyn Mine (MSc thesis, Applied Environmental Geology, Department of Geology, Cardiff University, UK).

Ure, A. M., \& Davidson, C. M. (1995). Chemical speciation in the environment. Black Academic and professional.

USEPA. (2008a). Building a scientific foundation for sound environmental decision. Retrieved from www.Epa.gov/ord/lrp

USEPA. (2008b). Science in action: Land research programme. Retrieved from www.Epa.gov

Van Loon, J. C. (1975). Heavy metals and environment. Proceedings of International conference on heavy metal in the environment (p. 349).

Webster, G. K., \& Karmahan, J. W. (1992). Element specific: Chromatographic detection by atomic emission spectroscopy. American Chemical Society Synposium, 479, 218.

Wedepol, K. H. (1991). Metals and their compounds in the environment (pp. 3-17). Weinheim: VCH.

WHO Lead NGR. (2010). Retrieved from http://www.who.int/scr/don/2010_07_07/en/index.html

Wuana, R. A., \& Okieimen, F. E. (2011). Heavy metals in contaminated soils: A review of sources, chemistry, risks and best available strategies for remediation. ISRN Ecology, 2011, 402647, 20.

\section{Copyrights}

Copyright for this article is retained by the author(s), with first publication rights granted to the journal.

This is an open-access article distributed under the terms and conditions of the Creative Commons Attribution license (http://creativecommons.org/licenses/by/3.0/). 